\title{
Prevalence of Mobile Phone Addiction among Students in Institute
}

\section{Technical of Kut}

\author{
Sameeha Naser Abed* \\ Israa Dawood Salim***
}

\author{
Rawaa Kamel Abd** \\ Nadia Abdul Razzaq Jamal****
}

\section{ABSTRACT}

Background and aim: The mobile phones have considerably the new epidemic of this century .It is a two edge sword, it has both the positive and negative consequences. The objective of this study was to determine the prevalence of mobile phone addiction among students in institute technical of Kut, and also to determine significant demographic associations.

Materials and method: A descriptive cross-sectional survey was performed using a self-administered questionnaire on a sample of 380 randomly selected students. A survey was carried out in the $1^{\text {st }}$ of April to the $1^{\text {st }}$ of July 2017. Data analysis by using the Minitab, version 18 .

Results: About $66 \%$ of the students were females. The overall prevalence of mobile phone addiction was $60 \%$ in studying students (35.37\% among male and $64.63 \%$ among female), with large increases in both sexes aged less or equal twenty years $(59.21 \%)$. There is no significant relationship between gender and demographic characteristics and there was no any significant relationship between demographic factors ( gender, residence, marital status, and employment status) with mobile phone addiction, while was a significant association between mobile phone addiction and age groups.

Conclusions: Overall female had more effects of mobile phone usage compared to male. Statistically significant difference was also observed for mobile phone addiction and age groups. There is a no significant relationship between demographic factors, gender, residence, marital status, and employment status with mobile phone use.

Recommendations: The recommendations of the present study are necessary to develop a mobile phone addiction preventive measure and controlling the mobile phone use. In addition to implementing effective education and intervention strategies such as behavior modification, the promotion of healthier free-time activities, and providing a healthy living environment around youths. Counseling programs are recommended for raising awareness of families concerning mobile phone use.

Keywords: Addiction, Mobile phones, Health awareness.

\section{INTRODUCTION}

Worldwide, technology especially the mobile phone have considerably the new epidemic of this century (Mihir et. al., 2016).It has become an essential part of the modern community and necessities in the people's lifestyle over the past decade (Alderso, 2012; Sudhen, 2014)and gained unparalleled fame(Addo, 2013) because it facilitates communication between individuals, and shortening Distances, a good investment of time. In addition, It includes a wide spectrum of the social activities(Abu-Jedy, 2008). The mobile phone is a two edge sword, it has both the positive and negative consequences(Billiexet. al., 2008; Ahmedet. al, 2011). Excessive mobile phone use tends to lead to the creation of a non-chemical addiction, most commonly known as " mobile phone addiction"(Suleimanet. al., 2015). The highest consumer of such devices is the youth(Pundiret. al, 2016)which a vulnerable group(Ranjan,2014) particularly students (McCarty, 2015). Despite mobile phone importance, numerous studies have focused on college students because the negative impact of addiction of mobile devices of psychological, social and academic performance(Jiaoet. al., 2015).Furthermore, emotional, financial, physical problems(Hanumanapuraet. al., 2016).Thus, the first objective of this study was to determine the prevalence of mobile phone addiction among students in institute technical of Kut. The second objective was to determine significant demographic associations.

\footnotetext{
* Master Community Health Tech. in institute technical of Kut. nassers34@yahoo.com

** Master Community Health Tech. in institute technical of Kut.

*** Master Community Health Tech. in institute technical of Hilla .

**** Master Community Health Tech. in institute technical of Mosul .
} 


\section{MATERIALS AND MEHTOD}

A survey was conducted, to determine prevalence of mobile phone addiction among students, this study was conducted as a descriptive study (cross section study). The study was carried out for a period of 4 months from the $1^{\text {st }}$ of April to the $1^{\text {st }}$ of July 2017.A random sampling method was conducted on a calculated sample of 600 students, A randomly sampling method was conducted on a calculated sample of 600 students, with response rate of $63.33 \%$, Therefore, the further analysis is for the 380 students male and 250 female) who were studying in $1^{\text {st }}$ and $2^{\text {rd }}$ year in institute technical of kut in wassit governorate was one of the formations Central Technical University. It is situated in the south of the center of Kut in Wassit governorate. who were studying in $1^{\text {st }}$ and $2^{\text {rd }}$ year in institute technical of Kut in Wassit Governorate was one of the formations Central Technical University. It is situated in the south of the center of Kut in Wassit governorate. All students were above 18 years of age, of both genders, studying in $1^{\text {st }}$ and $2^{\text {rd }}$ in institute technical in Kut in Wassit governorate, and who agreed to participate in the study. The questionnaire was a self-rating questionnaire was used for the collection of data. The first part of the questionnaire is consisting of the socio-demographic data this includes questions on basic socioeconomic characteristics (age, gender, marital status, living status, employment status, number of members in the family, place of residence, and type of dwelling. The second part was containing close ended questions regarding the mobile phone addiction. The level of mobile phone addiction among the students was determined by using the Mobile phone addiction questionnaire prepared by the researchers with the help of the experts panel that consists of 20 negative items. All questions were in 4-point Likert-scale, with answers being scored as follows: 1 refers to never and 2 refer to rarely, 3 refer to occasionally, and 4 refer to always. Then summed to provide a quantitative overall mobile phone addiction score in this 4-points scale varied, the minimum score is 20 , the maximum is 80 , and the Medium $=50$. The score from 20-49 is regarded as non-addicts, from 50-80 as Addicts. After obtaining verbal permission from institute technical of Kut in Wassit governorate and verbal approvals from the students, the purpose of the study were explained to the students, and students who willed to take part were included into the study. At the end of the survey, the data were analyzed using the Minitab, version 18. Descriptive and Chi square test were used in the data analysis. Chi square test was applied for quantitative and qualitative data respectively. The difference would be said to be significant when $p$-value $<0.05$.

\section{RESULTS}

\section{Students`gender}

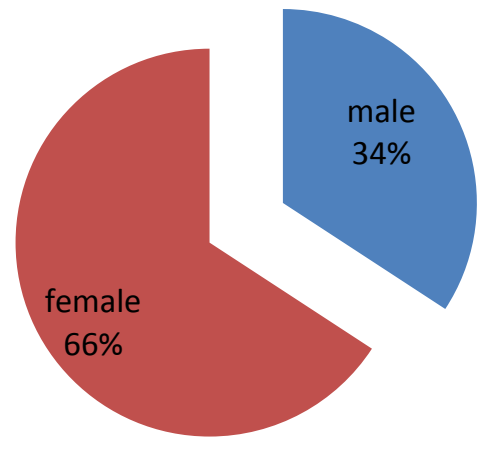

Figure (1) Distribution of the studied sample according to the gender. 


\section{Mobile phone adidiction level}

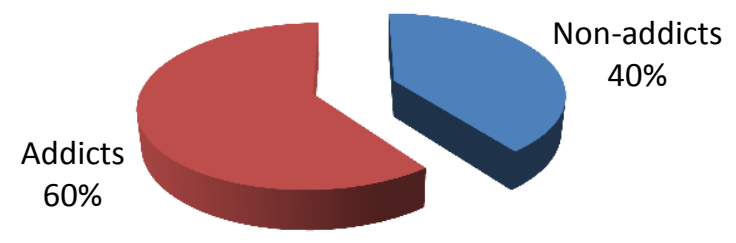

Figure (2) Distribution of the studied sample according to the mobile phone addiction

Table 1. Table-1: Socio-demographic characteristics of the study population

\begin{tabular}{|c|c|c|c|c|c|c|}
\hline \multirow{2}{*}{ Variables } & \multirow{2}{*}{ Groups } & \multirow{2}{*}{$\begin{array}{l}\text { Frequencies } \\
\text { and Percent }\end{array}$} & \multicolumn{2}{|c|}{ Gender } & \multirow{2}{*}{ Total } & \multirow[b]{2}{*}{ P-value } \\
\hline & & & Male & Female & & \\
\hline \multirow{6}{*}{ Age group } & \multirow{2}{*}{$\leq 20$} & Frequency & 74 & 151 & 225 & \multirow{6}{*}{0.513} \\
\hline & & \%Groups & 56.92 & 60.40 & 59.21 & \\
\hline & \multirow{2}{*}{$>20$} & Frequency & 56 & 99 & 155 & \\
\hline & & \%Groups & 43.08 & 39.60 & 40.79 & \\
\hline & \multirow{2}{*}{ Total } & Frequency & 130 & 250 & 380 & \\
\hline & & \%Groups & 100.00 & 100.00 & 100.00 & \\
\hline \multirow{6}{*}{$\begin{array}{l}\text { Employment } \\
\text { status }\end{array}$} & \multirow{2}{*}{ Employment } & Frequency & 10 & 23 & 33 & \multirow{6}{*}{0.621} \\
\hline & & \%Groups & 7.69 & 9.20 & 8.68 & \\
\hline & \multirow{2}{*}{ Unemployment } & Frequency & 120 & 227 & 347 & \\
\hline & & \%Groups & 92.31 & 90.80 & 91.32 & \\
\hline & \multirow{2}{*}{ Total } & Frequency & 130 & 250 & 380 & \\
\hline & & \%Groups & 100.00 & 100.00 & 100.00 & \\
\hline \multirow{6}{*}{ Residence } & \multirow{2}{*}{ Urban } & Frequency & 104 & 189 & 293 & \multirow{6}{*}{0.333} \\
\hline & & \%Groups & 80.00 & 75.60 & 77.11 & \\
\hline & \multirow{2}{*}{ Rural } & Frequency & 26 & 61 & 87 & \\
\hline & & \%Groups & 20.00 & 24.40 & 22.89 & \\
\hline & \multirow{2}{*}{ Total } & Frequency & 130 & 250 & 380 & \\
\hline & & \%Groups & 100.00 & 100.00 & 100.00 & \\
\hline \multirow{8}{*}{ Marital status } & \multirow{2}{*}{ Single } & Frequency & 100 & 215 & 315 & \multirow{8}{*}{0.067} \\
\hline & & \%Groups & 76.92 & 86.00 & 82.89 & \\
\hline & \multirow{2}{*}{ Married } & Frequency & 25 & 27 & 52 & \\
\hline & & \%Groups & 19.23 & 10.80 & 13.68 & \\
\hline & \multirow{2}{*}{ Others } & Frequency & 5 & 8 & 13 & \\
\hline & & \%Groups & 3.85 & 3.20 & 3.42 & \\
\hline & \multirow{2}{*}{ Total } & Frequency & 130 & 250 & 380 & \\
\hline & & \%Groups & 100.00 & 100.00 & 100.00 & \\
\hline
\end{tabular}

Table (2): Demographical characteristics amond participant students and mobile phone addiction category

\begin{tabular}{|c|c|c|c|c|c|c|}
\hline \multirow{2}{*}{ Variables } & \multirow{2}{*}{ Groups } & \multirow{2}{*}{$\begin{array}{l}\text { Frequencies } \\
\text { and Percent }\end{array}$} & \multicolumn{2}{|c|}{ mobile phone addiction level } & \multirow{2}{*}{ Total } & \multirow{2}{*}{ P-value } \\
\hline & & & Non-addicts & Addicts & & \\
\hline \multirow{6}{*}{ Age group } & \multirow{2}{*}{$\leq 20$} & Frequency & 77 & 148 & 225 & \multirow{6}{*}{0.008} \\
\hline & & \%Groups & 50.99 & 64.63 & 59.21 & \\
\hline & \multirow{2}{*}{$>20$} & Frequency & 74 & 81 & 155 & \\
\hline & & \%Groups & 49.01 & 35.37 & 40.79 & \\
\hline & \multirow{2}{*}{ Total } & Frequency & 151 & 229 & 380 & \\
\hline & & \%Groups & 100.00 & 100.00 & 100.00 & \\
\hline
\end{tabular}




\begin{tabular}{|c|c|c|c|c|c|c|}
\hline \multirow{6}{*}{ Gender } & \multirow{2}{*}{ Male } & Frequency & 49 & 81 & 130 & \multirow{6}{*}{0.557} \\
\hline & & \%Groups & 32.45 & 35.37 & 34.21 & \\
\hline & \multirow{2}{*}{ Female } & Frequency & 102 & 148 & 250 & \\
\hline & & \%Groups & 67.55 & 64.63 & 65.79 & \\
\hline & \multirow{2}{*}{ Total } & Frequency & 151 & 229 & 380 & \\
\hline & & \%Groups & 100.00 & 100.00 & 100.00 & \\
\hline \multirow{6}{*}{ Residence } & \multirow{2}{*}{ Urban } & Frequency & 111 & 182 & 293 & \multirow{6}{*}{0.176} \\
\hline & & \%Groups & 73.51 & 79.48 & 77.11 & \\
\hline & \multirow{2}{*}{ Rural } & Frequency & 40 & 47 & 87 & \\
\hline & & \%Groups & 26.49 & 20.52 & 22.89 & \\
\hline & \multirow{2}{*}{ Total } & Frequency & 151 & 229 & 380 & \\
\hline & & \%Groups & 100.00 & 100.00 & 100.00 & \\
\hline \multirow{8}{*}{$\begin{array}{l}\text { Marital } \\
\text { status }\end{array}$} & \multirow{2}{*}{ Single } & Frequency & 126 & 189 & 315 & \multirow{8}{*}{0.067} \\
\hline & & \%Groups & 83.44 & 82.53 & 82.89 & \\
\hline & \multirow{2}{*}{ Married } & Frequency & 23 & 29 & 52 & \\
\hline & & \%Groups & 15.23 & 12.66 & 13.68 & \\
\hline & \multirow{2}{*}{ Others } & Frequency & 2 & 11 & 13 & \\
\hline & & \%Groups & 1.32 & 4.80 & 3.42 & \\
\hline & \multirow{2}{*}{ Total } & Frequency & 151 & 229 & 380 & \\
\hline & & \%Groups & 100.00 & 100.00 & 100.00 & \\
\hline \multirow{6}{*}{$\begin{array}{l}\text { Employment } \\
\text { status }\end{array}$} & \multirow{2}{*}{ Employment } & Frequency & 18 & 15 & 33 & \multirow{6}{*}{0.069} \\
\hline & & \%Groups & 11.92 & 6.55 & 8.68 & \\
\hline & \multirow{2}{*}{ Unemployment } & Frequency & 133 & 214 & 347 & \\
\hline & & \%Groups & 88.08 & 93.45 & 91.32 & \\
\hline & \multirow{2}{*}{ Total } & Frequency & 151 & 229 & 380 & \\
\hline & & \%Groups & 100.00 & 100.00 & 100.00 & \\
\hline
\end{tabular}

\section{DISCUSSION}

Observing figure (1) is presenting the percentages of both sexes, out of total 380 students, 250 were female, and 130 were male students. The comparison of mobile phone addiction level in students is shown in figure (2). Table (1) presents the demographic characteristics such as gender, age, employment status, marital status and residence. This table consisted of 380 students (34\% males and $66 \%$ females). Most of the students with age $\leq 20$ years, which is the common age for students doing Diploma. The number of such students was 225 while over 20 years of age were 155 out of the 380. It could be noted from the following table that the highest frequency is of the students were unemployment that is 347 out of a total of 380 students. It could be seen in the following table that the majority of the students were residing in an urban area that is around $77 \%$. A $82.89 \%$ of the respondents were single. Overall, according to the results of the study, there is no significant relationship between gender and demographic characteristics. Comparison of social, demographic characteristics of study participants is shown in Table 2. Out of total 380 students, $60 \%$ were addicts and $40 \%$ were non addicts students. In both the groups, the half (50.99\% non addicts and $64.63 \%$ addicts) were with age $\leq 20$ years, and the difference was statistically significant. Both groups were comparable in terms of gender $(67.55 \%$ non addicts and $64.63 \%$ addicts) were female, and the difference was statistically nonsignificant. Area of residence $(73.51 \%$ non addicts and $79.48 \%$ addicts were from an urban area), and the difference was statistically nonsignificant. Marital status $(83.44 \%$ non addicts and $82.53 \%$ addicts were single, and the difference was statistically nonsignificant. The majority of non addicts students were non addicts (88.08\%) whereas $93.45 \%$ of addicts students were non addicts, and the difference was statistically nonsignificant.

The study consisted of 380 students, $34 \%$ males and $66 \%$ females. The results of this study agree with that of Pundir et. al., 2016 in India, who showed that the majority $(62 \%)$ were females. The highest percentage of students were at $\leq 20$ years $(59.21 \%)$. These findings agreed with what has been stated by Tripura, 2015 in India, who found that the highest percentages of students was at 17-20 years. The study shows that $91 \%$ of students were unemployment, the 
result goes with the findings obtained by Amidi and Rahmati, 2014 in Iran, who found that 80\% of students were unemployment.

Regarding residence, the highest percentage of students was urban $(77.11 \%)$ this finding was agreed with study D. Zalavadiyaet. al. (2016) in India,. It is worth mentioning that more than $82.89 \%$ of students included in the study were single These findings agreed with what has been stated by Amidi and Rahmati (2014)in Iran, who stated that single comprise $88 \%$ of the students.

The prevalence of mobile phone addiction has been $60 \%$ in studied students that was higher nearly $(20 \%)$ than the rate of addiction to mobile phones in Tavakolizadeh' study results, who reported that only $36.7 \%$ of students addicts to mobile phone. This study's results imply that the female is more likely subject to mobile phone addiction (64.63\%). Similar findings were reported by Maurya, 2014 in India, he found that $89 \%$ the students addict mobile phone were female. But this differs from a study conducted by Amidi and Rahmati (2014) in Iran, who found the prevalence of mobile phone addiction was $56.2 \%$ of female students and $64.5 \%$ of male students.The highest percentages of the students or $64.63 \%$ were from the age group of $\leq 20$ years of age. Most of the addicts students with $83.44 \%$ were single, while $15.23 \%$ were married, This was comparable to an Iranian study Tavakolizadeh, (2014), in which it was reported that he found that $78.4 \%$ of the addicts students were single and $18.9 \%$ were married A principal finding of this study was a significant association between mobile phone addiction and age groups which these findings are not in accordance with study results by Shokouhi, and Nadire (2015), who noted that was no significant association between mobile phone addiction level and age groups. On the other hand, the results suggested that there was no any significant relationship between demographic factors, gender, residence, marital status, and employment status with mobile phone use.

\section{CONCLUSION}

Overall female had more effects of mobile phone usage compared to male. Statistically significant difference was also observed for mobile phone addiction and age groups. There is a significant no relationship between demographic factors, gender, residence, marital status, and employment status with mobile phone use.

\section{RECOMMENDATIONS}

The recommendations of the present study are necessary to develop a mobile phone addiction preventive measure and controlling the mobile phone use. In addition to implementing effective education and interventional strategies such as behavior modification, the promotion of healthier free-time activities, and providing a healthy living environment around youths. Counseling programs are recommended for raising awareness of families concerning mobile phone use.

\section{REFERENCES}

Abu-Jedy Amjad. (2008). Mobile Phone Addiction and its Relationship with Self discloser among Sample of Students from University of Jordan and Amman AlAhliyya University. Jordan Journal of Educational Sciences. 4(2).

Addo Augustine. (2013). The adoption of mobile phone: How has it changed us socially? Issues in Business Management and Economics. 1(3). P.p.047-060.

Ahmed Ishfaq; Fiaz Tehmina Qazi. (2011). Mobile Phone Adoption and Consumption Patterns of University Students in Pakistan - International Journal of Business and Social Science. 2 (9).

Alderso, John n, B.A. (August , 2012) . A qualitative analysis of college students use of mobile phones for family communication. THESIS San Marcos, Texas

Amidi Maryam Mazaheri, Rahmati Fatemeh Najarkolae (2014). Cell Phone and Internet Addiction among Students inIsfahan University of Medical Sciences (Iran). Journal of Health Policy and Sustainable Health.1 (3). P.p.101-105.

Billiex Joe, Vander Martial Linden and Rochat Lucien. (2008). The Role of Impulsivity in Actual and Problematic Use of the Mobile Phone. Appled cognitive psychology. (Appl. Cognit. Psychol). 22. P.p.11951210

D. Dipeshkumar Zalavadiya, B. Niravkumar Joshi1, R. Bhavesh Kanabar, R. Jasmin Oza, V. Dhara Thakrar, H. Aarohi. Mitra. $(\uparrow \cdot 17)$ Comparative study of internet addiction between male and female students of a medical college of Gujarat. ScholarsJournal of Applied Medical Sciences (SJAMS). 4(8C). P.p.2936-294.2

Hanumanapura Shyam Rajanna, Kumar Manoj Sharma, Selvan Thamil Palanichamy. 
(2016). Exploration of technology use pattern among teenagers and its relationship with psychological variables. ASEAN Journal of Psychiatry. 17 (2).

Jiao Tianyu; Mitchell Nathaniel; Yan Runyu; Yang Xin; Zhong Jingyi. (2015). Relationships between MobilePhone/Internet Usage and Socioeconomic Development Level. International Journal of Humanities and Social Science. 5(10,1).

Maurya Parul, Penuli Yogita, Kunwar

Ashutosh, Lalia Hemlata,Negi Anjana Versha, VandanaWilliams Thakur. (2014). Impact of Mobile Phone Usage on Psychosocial Wellbeing of Student Nurses . IOSR Journal of Nursing and Health Science (IOSR-JNHS). 3(6 ). P.p. 39-42.

McCarty Eserinune MOJAYE. (2015). Mobile Phone usage among Nigerian University students and its impact on teaching and learning. Global Journal of Arts Humanities and Social Sciences. 3(1). P.p.29-38.

Mihir, Rupani P.; Khushali, Parikh D.; Atul, Trivedi V.; Manindra, Singh P.; Ayushi, Patel; Bhakti, Vadodariya; Bharat, Bhagora; Bhawana, Sharma. (2016). Cross- sectional study on mobile phone involvement among medical students of a tertiary care teaching hospital of western India . National Journal of Community Medicine.7(7).

Pundir Prachi, Andrews Teddy, V. S Binu., Kamath Ramachandra. (2016). Association of problematic mobile phone use with psychological distress and selfesteem among college students in South India: a cross-sectional study. International Journal of Community Medicine and Public Health. 3(10). P.p.2841-2849.
Ranjan Jyoti Muduli. (2014). Addiction to Technological Gadgets and Its Impact on Health and Lifestyle: A Study on College Students. (Thesis submitted for the partial fulfilment of Master's Degree in Development Studies).Roll no 412 HS1004.

Department of Humanities and Social Sciences National Institute of Technology, Rourkela - 769008 India.

Shokouhi Sahar Tabrizi and Cavus Nadire. (2015). A study to determine of students`smartphone usage status : a case study in near east university. The International Journal of Human, Community and Technology. 1 (2).

Sudhen K.A. Sumesh Kumar (2014). MSC (N). Mobile phone and adolescents- addiction a mindful check in . International Journal of Advanced Nursing Studies. 3 (1). P.p. 4246.

Suleiman Hafidha Al-Barashdi; Bouazza

Abdelmajid; and H. Naeema Jabur (2015). Smartphone Addiction among University Undergraduates: A Literature Review. Journal of Scientific Research and Reports. 4(3). P.p.210-225, ISSN: 23200227.

Tavakolizadeh Jahanshir; Atarodi Alireza; Ahmadpour Siravan; Pourgheisar Amir,Razavi. (2014). The Prevalence of Excessive Mobile Phone Use and its Relation With Mental Health Status and Demographic Factors Among the Students of Gonabad University of Medical Sciences in 2011 - 2012. Int J Med. 2(1). P.p.e15527.

Tripura T Sundari. (2015). Effects of mobile phone use on academic performanceof college going young adults in India. International Journal of Applied Research.1(9). P.p.898-905. 